\title{
Antibody 'markers' in Crohn's disease: opportunity or overstatement?
}

Crohn's disease results from an interaction among host and environmental factors. The host contribution includes genetic predisposing factors, neuroendocrine modifying effects, and immunological effector mechanisms. The most likely environmental influences are the luminal enteric microflora. Tissue damage in Crohn's disease is immune mediated and more than one mechanism may be involved. Evidence for and against a primary autoimmune mechanism has been reviewed elsewhere and it seems unlikely that autoimmune reactivity is of direct pathogenic importance in Crohn's disease. ${ }^{1}$ Thus, although autoimmune phenomena including autoantibodies and selfreactive lymphocytes have been reported in Crohn's disease, the condition is not strictly speaking a true autoimmune disease in so far as tissue damage is not directly caused by these autoimmune effectors. ${ }^{12}$ Notwithstanding, detection of autoantibodies and other immunological 'markers' may have clinical and research potential in inflammatory bowel disease (Table I).

In this issue, Seibold et al (see page 481) report the prevalence of pancreatic antibodies in serum samples of patients with Crohn's disease and their relatives. This is an extension of previous work by these and other investigators who have found pancreatic autoantibodies in about one third of patients with Crohn's disease. ${ }^{3}$ Two patterns of antibody reaction have been observed based on staining of pancreatic tissue by indirect immunofluorescence. Despite their low prevalence, these antibodies have a high degree of specificity for Crohn's disease. In contrast to other immunologically mediated disorders, such as chronic active hepatitis and primary biliary cirrhosis, autoantibody detection in inflammatory bowel disease does not have an important role in clinical diagnosis. This situation may now be changing with reports of several antibodies in both Crohn's and ulcerative colitis (Table II).$^{2-9}$ The diagnostic importance and predictive value of combined results from a panel of these antibodies merits investigation. However, as with any putative diagnostic test, rigorous prospective analysis is required and premature, exaggerated claims should be avoided. Most of the consistently detectable antibodies associated with either form of inflammatory bowel disease do not correlate with disease activity (Table II). Therefore, variation in antibody titres has no apparent clinical value.

TABLE I Potential significance of antibody markers in Crohn's disease

\footnotetext{
Diagnostic marker, alone or in conjunction with other antibodies Marker of disease activity

Marker of (genetic) susceptibility

Marker of disease heterogeneity

Marker of underlying immune dysregulation and cross reactivity with environmental agent

Opportunity to bridge clinical and basic science by molecular identification of antigen
}

TABLE II Antibody markers in Crohn's disease and ulcerative colitis

\begin{tabular}{llllll}
\hline Antibody & $\begin{array}{l}\text { Crohn's } \\
\text { disease }\end{array}$ & $\begin{array}{l}\text { Ulcerative } \\
\text { colitis }\end{array}$ & $\begin{array}{l}\text { Correlation } \\
\text { with activity }\end{array}$ & $\begin{array}{l}\text { Familial } \\
\text { aggregation }\end{array}$ & Reference \\
\hline PAB & ++ & - & - & - & 3 \\
pANCA & + & +++ & - & \pm & 4,5 \\
AEA-15 & ++ & + & - & $?$ & 6 \\
AECA & + & ++ & + & $?$ & 7 \\
ASCA & ++ & - & - & $?$ & 8 \\
Lymphocytotoxic & ++ & + & - & + & 2 \\
Epithelial antibodies & + & ++ & - & + & 2 \\
Anti-p40 (40 kDa) & - & +++ & \pm & $?$ & 2,9 \\
\hline
\end{tabular}

$\mathrm{PAB}=$ pancreatic autoantibody; pANCA=anti-neutrophil cytoplasmic antibody; AEA-15=anti-erythrocyte antibody; AECA=anti-endothelial cell antibody; ASCA=anti-Saccaromyces cerevisiae; anti-p $40=$ antibody reactive to a $40 \mathrm{kDa}$ epithelial protein described by Das et al.

Although a familial association was not found for pancreatic autoantibodies in the study by Seibold et al, some autoantibodies may be markers of susceptibility. This is well established in the case of islet cell antibodies as predictive markers for insulin dependent diabetes. The potential role of autoantibodies as markers of susceptibility or genetic markers in inflammatory bowel disease has been controversial and may be confounded by the complexity of the genetics of inflammatory bowel disease, ethnicity, and disease heterogeneity. ${ }^{4}$ The concept of Crohn's disease as a heterogeneous syndrome rather than a single entity is popular at present, and stratification of apparent subsets has been attempted based on autoantibody status. For example, perinuclear anti-neutrophil cytoplasmic antibodies (pANCA) have been proposed as a defining characteristic of a subgroup of Crohn's disease with ulcerative colitis-like features. ${ }^{5}$ Whether pancreatic autoantibody status or the two reported patterns of pancreatic antibody reactivity reflect underlying heterogeneity, is speculative at present.

There is no conclusive evidence for a direct pathogenic role for any autoantibody in inflammatory bowel disease. ${ }^{1}$ This is likely to be true also for pancreatic autoantibodies. Clinically important pancreatitis is uncommon in Crohn's disease and is usually related to gallstones, duodenal involvement, or drug induced, although there is circumstantial evidence for subclinical pancreatic involvement as an extraintestinal association. ${ }^{3}$ Autoantibodies in Crohn's disease and ulcerative colitis are probably markers of an underlying mucosal immune dysregulation in patients with these disorders. The possibility of cross reactivity with enteric microbial antigens is conceptually appealing. There are several well documented examples of autoantibody responses triggered by environmental stimuli including drugs and microbes, and recent evidence suggests that pANCA are generated in inflammatory bowel disease as a mucosal immune response, perhaps to enteric microbial antigens. ${ }^{10}$

In conclusion, autoantibodies are unlikely to have a direct, primary pathogenic role in Crohn's disease, and 
their diagnostic value is, at best, uncertain. However, their potential contribution to understanding disease heterogeneity and underlying immunological mechanisms is intriguing. Molecular identification of the antigen to which pancreatic and other autoantibodies are reactive in Crohn's disease will help resolve questions of heterogeneity, assay specificity, and mechanism of autosensitisation. The study of autoantibodies in other conditions has helped to clarify the molecular structure and function of several intracellular molecules. In this context, autoantibodies have been viewed as important bridges between clinical and basic sciences. ${ }^{11}$

Department of Medicine, Cork University Hospital, Cork, Ireland

\section{FERGUS SHANAHAN}

1 Shanahan F, Targan S. Mechanisms of tissue injury in inflammatory bowel disease. In: Targan $S$, Shanahan $\mathrm{F}$, eds. Inflammatory bowel disease: from bench to bedside. Baltimore: Williams and Wilkins, 1994:78-88.
2 Shanahan $\mathrm{F}$. The role of autoantibodies and autoimmunity in chronic inflammatory disorders of the gut. Curr Opin Gastroenterol 1992; 8: infiamma 992

3 Seibold F, Weber $\mathrm{P}$, Jenss $\mathrm{H}$, Wiedmann $\mathrm{KH}$. Antibodies to a trypsin sensitive pancreatic antigen in chronic inflammatory bowel disease: specific markers for a subgroup of patients with Crohn's disease. Gu 1991; 32: 1192-7.

4 Shanahan F. Neutrophil autoantibodies in inflammatory bowel disease: Are they important? Gastroenterology 1994; 107: 586-9.

5 Vasiliauskas EA, Plevy SE, Landers CJ, Binder SW, Ferguson DM, Yang $\mathrm{H}$, et al. Perinuclear antineutrophil cytoplasmic antibodies in patients with Crohn's disease define a clinical subgroup. Gastroenterology 1996; 110: 1810-9.

6 Berberian LS, Valles-Ayoub Y, Gordon LK, Targan SR, Braun J Expression of a novel autoantibody defined by VH3-15 gene in inflammatory bowel disease and Campylobacter jejuni enterocolitis. $\mathcal{f}$ Immunol 1994; 153: 3756-63.

7 Stevens TR, Harley SL, Groom JS, et al. Anti-endothelial cell antibodies in inflammatory bowel disease. Dig Dis Sci 1993; 38: 426-32.

8 Sendid B, Colombel JF, Jacquinot PM, et al. Specific antibody response to oligomannosidic epitopes in Crohn's disease. Clin Diag Lab Immunol

9 Biancone L, Mandal A, Yang H, et al. Production of immunoglobulin G and $\mathrm{Gl}$ antibodies to cytoskeletal protein by lamina propria cells in ulcerative colitis. Gastroenterology 1995; 109: 3-12.

10 Targan SR, Landers CJ, Cobb L, MacDermott RP, Vidrich A. Perinuclear anti-neutrophil cytoplasmic antibodies are spontaneously produced by mucosal B cells of ulcerative colitis patients. F Immunol 1995; 155: 3262-7.

11 Tan EM. Interactions between autoimmunity and molecular medicine and cell biology. Bridges between clinical and basic sciences. 7 Clin Invest 1989; 84: 1-6. 